\title{
Application of the Caprini Risk Assessment Model for the Assessment of Risk Factors for Postoperative Venous Thromboembolism in the Surgery Department of Anosiala University Hospital
}

Jean Baptiste Ramampisendrahova ${ }^{1}$, Andriamanantsialonina Andrianony ${ }^{1}$, Aina Andrianina Vatosoa Rakotonarivo ${ }^{1}$, Mamisoa Bodohasina Rasamoelina ${ }^{2}$, Eric Andriantsoa ${ }^{2}$, Rado Razafimahatratra $^{1}$, Gaëtan Duval Solofomalala ${ }^{1}$

*Corresponding Email: ramampisendra@ gmail.com

${ }^{1}$ Department of Orthopedic Surgery, Anosiala University Hospital Center, Antananarivo, Madagascar

${ }^{2}$ Department of Digestive and Urological Surgery, Anosiala University Hospital Center, Antananarivo, Madagascar

Received: April 19, 2021

Received in Revised: June 2, 2021

Accepted: June 16, 2021

\section{Abstract}

The purpose of this research is to ascertain the prevalence of postoperative venous thromboembolism in the Department of Surgery at Anosiala University Hospital and to identify risk factors for developing postoperative venous thromboembolism using the Caprini Risk Assessment Model. From December 2017 to October 2019, this was a 22-month prospective cohort research conducted at Anosiala University Hospital. It included all adult patients over the age of 18 who were operated on in an emergency or on a planned basis by the Department of Surgery. This research included 662 participants. Within 30 days after surgery, the risk of venous thromboembolism was 0.3 percent. According to the overall Caprini score, 25.2 percent of patients were classified as having a low risk of venous thromboembolism, 25.2 percent as having a moderate risk, 29.5 percent as having a high risk, and 20.1 percent as having the greatest risk. Patients in the highest risk category (scoring 5) had a substantially increased chance of having venous thromboembolism after surgery $(\mathrm{p}=0.0007)$. Only major open surgery was related with a statistically significant increase in postoperative venous thromboembolism $(\mathrm{p}=0.028)$. Age 75 years, elective arthroplasty, and hip, pelvic, or leg fractures were not linked with postoperative venous thromboembolism statistically significantly ( $p>0.05)$. Our findings indicate that the Caprini risk assessment model might be used successfully to avoid postoperative venous thromboembolism in surgical patients in Madagascar, since patients in the highest risk category had a considerably increased chance of developing postoperative venous thromboembolism.

Keywords: Venous Thromboembolism, Postoperative, Caprini

\section{Introduction}

VTE, which comprises deep vein thrombosis (DVT) and pulmonary embolism (PE), is the greatest cause of death after surgical treatments (Tadesse et al., 2020). Up to 20\% of all new occurrences of venous thromboembolism are caused by recent surgery (Nicholson et al., 2020). Between 350000 to 900000 persons acquire VTE in the United States, with around 100,000 dying (Tadesse et al., 2020). Its frequency after surgery ranged between 2.4 and 9.6 percent in Africa (Danwang et al., 2017). Risk assessment is the first step in avoiding the beginning of postoperative VTE; since the Caprini Risk Assessment Model (Caprini RAM) is widely used internationally, it is also used at our hospital's Surgery department for thromboembolic risk 
assessment. The purpose of this research is to ascertain the prevalence of postoperative VTE in the surgical department of the Anosiala University Hospital and to identify risk factors for developing this kind of VTE utilizing the Caprini RAM.

\section{Methods}

From December 2017 to October 2019, a 22-month prospective cohort study was conducted at the Anosiala University Hospital in Antananarivo, Madagascar, involving all adult patients over the age of 18 who were operated on urgently or scheduled in the departments of Orthopedic Surgery, Visceral and Urological Surgery, and Neurosurgery. This research did not involve any patients under the age of eighteen.

\section{Study procedure}

Each file of patients to be operated on was added a Caprini RAM form (Figure 1), completed by the specialist intern in Surgery or the Surgeon. Patients were classified according to risk scores. After discharge from the hospital, patients were instructed to return to the hospital if symptoms of VTE developed at home in order to screen for the onset of venous thromboembolism within 30 days after surgery.

\section{Caprini Risk Assessment Model (Caprini RAM)}

Patients with medical and surgical problems were given the Caprini risk assessment score to help them stick to their preventative VTE regimens. Each risk factor was given a score ranging from one to five points based on its impact on the chance of thrombosis. Individualized risk indicators were assessed and then added together to give a cumulative risk score that was used to categorize patients into four risk categories: "low risk" ( 0 to 1 point), "moderate risk" (2 points), "high risk" (3 to 4 points), and "highest risk" (5 points) (Caprini, JA, 2005).

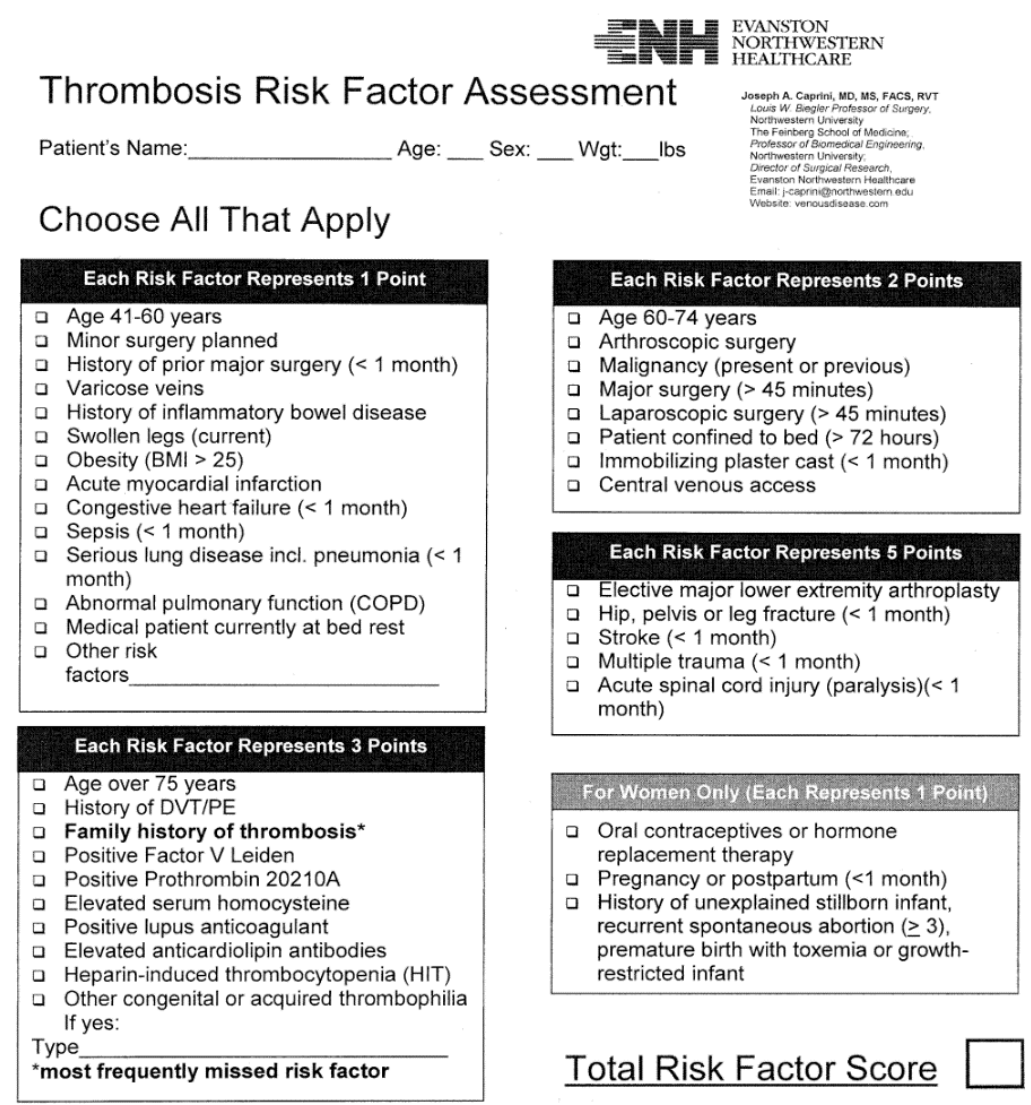

Figure 1: Caprini Risk Assessment Model (Caprini, JA, 2005) 


\section{Diagnosis of venous thromboembolic disease.}

Patients with symptoms such as swelling, discomfort, and tenderness in one or both legs, significant discomfort in the calf when the foot was flexed, and a sense of heat surrounding the swollen region were suspected of having DVT; a venous Doppler ultrasonography was used to confirm the diagnosis. Patients who had a high suspicion of pulmonary embolism, such as inexplicable dyspnea, chest discomfort while breathing in, or even rapid collapse, were given a chest CT angiography.

\section{Statistical analysis}

Microsoft Excel 2013 was used to keep track of all patient information. The proportion of patients with each risk factor for Caprini was calculated using descriptive statistics. The frequency of VTE per risk score category was determined using the distribution of the Caprini score. In univariate analysis, the incidence of VTE was considered as a dependent variable, while the independent variables (individual risk factors and Caprini score) were statistically significant indices. If the p-value was less than 0.05 , the findings were deemed statistically significant. The Epi info 7.0 program was used to conduct all analyses.

\section{Results and Discussion}

In this research, 662 participants were enrolled. The patients were divided into $37.9 \%$ males and 62.1 percent women, with an average age of 43.5 years and extremes of 18 and 88 years. The patients were separated into three groups: 326 for Orthopedic Surgery and Traumatology (49.2\%), 325 for Digestive and Urological Surgery (49.1\%), and 11 for Neurosurgery (11.2\%). (1.7 percent ). Within 30 days after surgery, two patients had VTE, resulting in a worldwide incidence of 0.3 percent. According to the Caprini score, 25.2 percent of patients $(n=167)$ were in the low risk category for VTE, 25.2 percent $(n=167)$ were in the moderate risk group, 29.5 percent $(n=195)$ were in the high risk group, and 20.1 percent $(n=133)$ were in the highest risk group. Patients in the extremely high risk category (scoring 5) had a substantially greater chance of experiencing postoperative VTE $(\mathrm{p}=0.0007)$ after univariate analysis.

Table 1: The Caprini scores and postoperative venous thromboembolism

\begin{tabular}{|l|c|c|c|c|}
\hline Caprini score & $\begin{array}{c}\text { Number of } \\
\text { patients (\%) }\end{array}$ & $\begin{array}{c}\text { Number of } \\
\text { patients without } \\
\text { VTE (\%) }\end{array}$ & $\begin{array}{c}\text { Number of } \\
\text { patients with } \\
\text { VTE (\%) }\end{array}$ & $\boldsymbol{p}$-value \\
\hline 0 à 1 & $167(25,2)$ & 167 & 0 & \\
\hline 2 & $167(25,4)$ & 167 & 0 & \\
\hline 3 à 4 & $195(29,5)$ & 195 & 0 & \\
\hline$\geq 5$ & $133(20,1)$ & 131 & 2 & $p=0,0007$ \\
\hline Total & $662(100,0)$ & 662 & $2(0,3)$ & \\
\hline
\end{tabular}

Individual risk variables were detected in 19 of the 39 risk variables in the Caprini risk assessment model in our patients, five of whom had venous thromboembolism within 30 days after surgery. Only major open surgery $(\mathrm{p}=0.028)$ was discovered as a significant predictor of postoperative VTE among the five criteria described in Epi info.7. Elective arthroplasty and hip fractures, pelvis, or leg were not statistically significantly linked with postoperative VTE (p>0.05) when compared to age over 75 years (Table 2).

Table 2: The individual risk factors and postoperative venous thromboembolism

\begin{tabular}{|l|c|c|c|c|}
\hline \multicolumn{1}{|c|}{ Risk factor } & $\begin{array}{c}\text { Patients } \\
\text { number }\end{array}$ & $\begin{array}{c}\text { Patients number } \\
\text { without VTE }\end{array}$ & $\begin{array}{c}\text { Patients number } \\
\text { with VTE }\end{array}$ & $\boldsymbol{p}$-value \\
\hline Age 41-60 years & 243 & 243 & 0 & \\
\hline
\end{tabular}




\begin{tabular}{|c|c|c|c|c|}
\hline Minor surgery planned & 281 & 281 & 0 & \\
\hline \multicolumn{5}{|l|}{$\begin{array}{l}\text { History of prior major surgery } \\
(<1 \text { month) }\end{array}$} \\
\hline Obesity (BMI > 25 kg/m2) & 14 & 14 & 0 & \\
\hline Swollen leg & 2 & 2 & 0 & \\
\hline Varicose veins & 3 & 3 & 0 & \\
\hline Sepsis (<1 month) & 1 & 1 & 0 & \\
\hline Serious Lung disease $(<1$ month $)$ & 0 & 0 & 0 & \\
\hline Abnormal pulmonary function & 0 & 0 & 0 & \\
\hline Acute myocardial infarction & 0 & 0 & 0 & \\
\hline $\begin{array}{l}\text { Congestive heart failure }(<1 \\
\text { month) }\end{array}$ & 1 & 0 & 1 & \\
\hline $\begin{array}{l}\text { History of inflammatory bowel } \\
\text { disease }\end{array}$ & 0 & 0 & 0 & \\
\hline $\begin{array}{l}\text { Medical patient currently at bed } \\
\text { rest }\end{array}$ & 0 & 0 & 0 & \\
\hline $\begin{array}{l}\text { History of unexplained stillborn } \\
\text { infant , recurrent spontaneous } \\
\text { abortion }\end{array}$ & 0 & 0 & 0 & \\
\hline $\begin{array}{l}\text { Oral contraceptives or hormone } \\
\text { replacement therapy }\end{array}$ & 3 & 3 & 0 & \\
\hline Pregnancy or postpartum & 3 & 3 & 0 & \\
\hline Age $61-74$ years & 88 & 88 & 0 & \\
\hline Arthroscopic surgery & 0 & 0 & 0 & \\
\hline Major surgery (>45minutes) & 381 & 379 & 2 & $\begin{array}{c}p= \\
0,028\end{array}$ \\
\hline Laparoscopic surgery & 0 & 0 & 0 & \\
\hline Malignancy & 9 & 9 & 0 & \\
\hline $\begin{array}{l}\text { Patient confined to bed (>72 } \\
\text { hours) }\end{array}$ & 18 & 18 & 0 & \\
\hline $\begin{array}{l}\text { Immobilizing plaster cast } \\
(<1 \text { month })\end{array}$ & 8 & 8 & 0 & \\
\hline Central venous access & 0 & 0 & 0 & \\
\hline Age over 75 years & 28 & 27 & 1 & $p=0,389$ \\
\hline History of DVT/PE & 1 & 1 & 0 & \\
\hline Family history of thrombosis & 0 & 0 & 0 & \\
\hline Positive factor V Leiden & 0 & 0 & 0 & \\
\hline Positive Prothrombin 20210A & 0 & 0 & 0 & \\
\hline Positive Lupus anticoagulant & 0 & 0 & 0 & \\
\hline $\begin{array}{l}\text { Elevated anticardiolipin } \\
\text { antiboidies }\end{array}$ & 0 & 0 & 0 & \\
\hline Elevated serum homocysteine & 0 & 0 & 0 & \\
\hline $\begin{array}{l}\text { Heparin-induced } \\
\text { thrombocytopenia }\end{array}$ & 0 & 0 & 0 & \\
\hline $\begin{array}{l}\text { Other congenital or acquired } \\
\text { thrombophilia }\end{array}$ & 0 & 0 & 0 & \\
\hline Stroke (<1month) & 0 & 0 & 0 & \\
\hline
\end{tabular}




\begin{tabular}{|l|c|c|c|c|}
\hline $\begin{array}{l}\text { Elective major lower extremity } \\
\text { arthroplasty }\end{array}$ & 47 & 46 & 1 & $p=0,456$ \\
\hline $\begin{array}{l}\text { Hip, pelvis or leg fracture } \\
(<1 \text { month })\end{array}$ & 126 & 125 & 1 & $p=0,067$ \\
\hline Multiple trauma & 0 & 0 & 0 & \\
\hline $\begin{array}{l}\text { Acute spinal cord injury }(<1 \\
\text { month) }\end{array}$ & 303 & 302 & 1 & $p=0,089$ \\
\hline Age $<40$ years & & & & \\
\hline
\end{tabular}

One of the well-defined surgical consequences is venous thromboembolism. This thrombotic event is related with a mortality rate of 7 to 65 percent in trauma patients, 25 to 33 percent in general surgical operations, and 41 to 85 percent following total hip arhroplasty, total knee arthroplasty, and other orthopedic surgeries (Jeong et al., 2014). Recent surgery was shown to be a provoking factor in up to $20 \%$ of all new instances of venous thromboembolism (Nicholson et al., 2020). The risk of venous thromboembolism after surgery was determined to be 0.3 percent in our research. This rate is similar to that of Vietnamese patients in Hanh BM et al(Hanh .'s et al., 2019) study, which identified 3068 cases out of 2790027 patients at 90 days $(0.1 \%)$, but significantly lower than that of Tadesse TA et alstudy .'s at Tikur Anbessa Ethiopia hospital, which reported a rate of 1.93 percent (Tadesse et al., 2020), and in American plastic and (Jeong et al., 2014).

In 1991, the Caprini Risk Assessment Model was published for the first time. To reflect new findings and a better knowledge of the predictors of VTE, this model was improved and updated to its most extensively used form in 2005. (Golemi and colleagues, 2019). Low-risk patients are exempt from postoperative anticoagulation prophylaxis because the risk of anticoagulation bleeding is less than or equal to the risk of venous thromboembolic events at 30 days. High-risk patients are at a high risk of postoperative venous thromboembolism and should be given anticoagulant protection for 30 days (Caprini, JA, 2005, Golemi et al., 2019). The concept that patients with a high Caprini score have a much increased risk of developing postoperative venous thromboembolism has been verified in studies. The risk of venous thromboembolism rose in the score group 7-8, according to Hanh BM et al (Hanh et al., 2019), as compared to the score groups 3-4 or 5-6. Patients in the low and moderate risk categories had an incidence of DVT of less than 0.5 percent, whereas more than half of the patients with DVT were in the highest risk category, according to Bo $\mathrm{H}$ et al (Bo et al., 2020). Our findings complement the literature's findings, demonstrating a substantial increase in the risk of venous thromboembolic events in correlation with an increase in Caprini score of $5(\mathrm{p}=0.0007)$.

When it comes to individual risk factors, Only extensive open surgery $(p=0.028)$ was substantially linked with a higher risk of postoperative venous thromboembolism among the five criteria described in Epi info.7. While the risk variables (one month of congestive heart failure, 75 years of age, elective arthroplasty, hip, pelvic, or leg fracture) were not. Although age under 40 is not one of the Caprini RAM risk factors, we did find a case in a 28 -year-old male, although the statistical analysis was not significant $(\mathrm{p}=0.089)$. This finding contradicts previous research. Older age, acute myocardial infarction, heart and respiratory failure, acute lung disease, renal failure, hypertension, immobility, cancer, varicose veins, and peripheral vascular disease were all found to be significantly associated with postoperative venous thromboembolism in a study conducted by Hanh BM et al (Hanh et al., 2019), while malignancy and chronic obstructive pulmonary disease were not. The presence of a central venous catheter on admission, personal or family history of VTE, admission or treatment of cancer in the previous year, and present immobility were among the most powerful independent predictors of VTE, according to Grant PJ et al (Grant et al., 2016). Sepsis, central venous 
access, congestive heart failure, history of VTE, and a high Caprini risk score were the characteristics that were related with the greatest risk of developing VTE in thoracic surgery patients at the Boston Medical Center (Sterbling et al., 2018).

The limited sample size, the manner of data collection, and the variation in the research population might all contribute to the discrepancy shown in our research. The monocentric study's primary weakness was the limited number of cases (just two patients had a VTE event).

Even although the significance of the findings of some specific risk variables differs from those of other authors, our research backs up the existing literature on the significant risk of developing postoperative VTE in patients with a high Caprini score. This research presents findings on the prevention of postoperative VTE and throws light on the applicability of VTE preventive measures in surgical patients in Madagascar. We advocate using the Caprini risk assessment model for the calculation of thromboembolic risk in surgical populations since it is less onerous and simpler to operationalize.

\section{Conclusion}

For each patient's postoperative venous thromboembolism risk assessment, the Caprini risk assessment paradigm is easy to implement. Because patients in the highest risk category had a much greater chance of developing postoperative venous thromboembolism, the findings of our research indicate that this strategy might be utilized successfully to prevent postoperative venous thromboembolism in surgical patients in Madagascar.

\section{Conflict of interest}

The authors declare no conflict of interest.

\section{Contributions from the authors}

All the authors contributed to the realization of this work. All authors also declare that they have read and approved the final version of the manuscript.

\section{References}

Tadesse, T.A., Kedir, H.M., Fentie, A.M., \& Abiye, A. A. (2020). Venous Thromboembolism Risk and Thromboprophylaxis Assessment in Surgical Patients Based on Caprini Risk Assessment Model. Risk management and healthcare policy, 13, 2545.

Nicholson, M., Chan, N., Bhagirath, V., \& Ginsberg, J. (2020). Prevention of venous thromboembolism in 2020 and beyond. Journal of Clinical Medicine, 9(8), 2467.

Danwang, C., Temgoua, M.N., Agbor, V.N., Tankeu, A.T., \& Noubiap, J.J. (2017). Epidemiology of venous thromboembolism in Africa: a systematic review. Journal of Thrombosis and Haemostasis, 15(9), 1770-1781.

Caprini, J. A. (2005). Thrombosis risk assessment as a guide to quality patient care. Diseasea-Month, 51(2-3), 70-78.

Jeong, H.S., Miller, T.J., Davis, K., Matthew, A., Lysikowski, J., Lazcano, E., ... \& Kenkel, J. M. (2014). Application of the Caprini risk assessment model in evaluation of nonvenous thromboembolism complications in plastic and reconstructive surgery patients. Aesthetic surgery journal, 34(1), 87-95.

Hanh, B.M., Cuong, L.Q., Son, N.T., Duc, D.T., Hung, T.T., Hung, D.D., ... \& Chu, D.T. (2019). Determination of risk factors for venous thromboembolism by an adapted caprini scoring system in surgical patients. Journal of personalized medicine, 9(3), 36. 
Bo, H., Li, Y., Liu, G., Ma, Y., Li, Z., Cao, J., ... \& Wu, X. (2020). Assessing the risk for development of deep vein thrombosis among Chinese patients using the 2010 Caprini risk assessment model: a prospective multicenter study. Journal of atherosclerosis and thrombosis, 27(8), 801-808.

Golemi, I., Adum, J.P.S., Tafur, A., \& Caprini, J. (2019). Venous thromboembolism prophylaxis using the Caprini score. Disease-a-Month, 65(8), 249-298.

Grant, P.J., Greene, M.T., Chopra, V., Bernstein, S.J., Hofer, T. P., \& Flanders, S.A. (2016). Assessing the caprini score for risk assessment of venous thromboembolism in hospitalized medical patients. The American journal of medicine, 129(5), 528-535.

Sterbling, H.M., Rosen, A.K., Hachey, K.J., Vellanki, N.S., Hewes, P.D., Rao, S.R., ,..\& Litle, V.R. (2018). Caprini risk model decreases venous thromboembolism rates in thoracic surgery cancer patients. The Annals of thoracic surgery, 105(3), 879-885. 